\title{
A GM-Based Profitable Duration Prediction Model for Chinese Crude Oil Main Production District
}

\author{
Jinlou Zhao, Yuzhen Han, and Lixia Ke \\ Harbin Engineering University, Heilongjiang, China, 150001 \\ zhaojinloulsina.com
}

\begin{abstract}
In this paper, a grey model (GM) based profitable duration forecasting approach is proposed for Chinese crude oil main production district. In this methodology, the forecasting functions on electricity expenditure and crude oil sales revenue are first built via GM. Based on these two forecasting functions, the profitable duration of crude oil production under the restriction of the coefficient of limit electricity cost is then worked out. Finally, some ways to prolong the profitable duration are put forward in order to offer some valuable suggestions for the transformation of resource-based cities.
\end{abstract}

Keywords: GM, profitable duration, crude oil, china, forecasting.

\section{Introduction}

Besides the ocean oil-fields, there are 19 land oil-fields in China. Among them, the annual crude oil output of Daqing Oil Field occupies 1/4 of the Chinese land oil-fields' output, which make Daqing a 'weatherglass' of Chinese crude oil market. Therefore, the Daqing Oil Field is one of the main crude oil production districts in China.

As is known to us, crude oil is a non-renewable resource. Although Daqing Oil Field Company actively explore outer petroleum resources, the crude oil output in Daqing Oil Field decreases year by year with the continuous exploitation of crude oil. Along with the exploitation, the moisture content of crude oil increases continuously. It results in that the main variable costs of oil exploitation - electricity consumption increases continuously, and thus leading to the increase of unit electricity consumption cost for crude oil production. In such situations, some ideas are presented. For example, if crude oil output decreases year by year, but electricity consumption increases year by year, then there must be a certain year that the crude oil sales revenue cannot afford to electricity expenditure in the Chinese crude oil main production district. Therefore this time point is extremely important for the sustainable development of resource-based cities. As earlier noted, beyond this time point, the crude oil output of crude oil main production districts will be no meaningful because the oil output after this time point will not bring any profits.

As we know, the Chinese crude oil main production districts such as Daqing and Yumen are the common resource-based cities. In order to keep the sustainable development of these resource-based cities, it is necessary to forecast the profitable duration. With this profitable duration, we can provide time basis for the 
resource-based cities' transformation and development strategies, which is the main motivation of this study.

The rest of this study is organized as follows. The next section describes the basic principle of calculating the profitable duration method. In Section 3, a practical example is given to present the computing process of the proposed methodology. Finally, some important ways to prolong the profitable duration and some valuable suggestions to the transformation-oriented resource-based cities are presented in Section 4.

\section{Basic Principle for Profitable Duration Computation}

Usually, the profitable duration of a main crude oil production district is defined as a time period that the crude oil sales revenues are larger than the electricity consumption expenditure for a certain crude oil production district. From this definition, our goal is to calculate the duration. For this purpose, we apply the limit electricity cost coefficient to arrive at this goal.

Generally, the limit electricity cost coefficient can be represented by

$$
\frac{\text { Electricity expenditure }}{\text { Crude oil sales revenue }}=\text { Coefficient of limit electricity cost }
$$

In the Equation (1), crude oil sales revenue and electricity expenditure are the future values and thus both oil sales revenue and electricity consumption expenditure are the function of time $t$. As Section 1 implied, the two functions are monotonic functions. Therefore, the time curves of the two functions may be intersected, the intersecting time is the non-profit time point. The time period covered from current to non-profit time point is the profitable duration. So far, our main task is to predict the non-profit time point.

From the above analysis, the key to the profitable duration is how to construct the crude oil sales revenue function and electricity consumption expenditure function regarding the time $t$. For this, we applied to grey model proposed by Deng [1] to construct the above two functions. For grey model, interested readers can refer to Deng [1] for more details.

The generic idea of calculating the profitable duration for crude oil main production district is composed of the following steps.

Step I: using grey forecasting model GM $(1,1)$ to obtain time function of annual crude oil output $x$ and annual electricity consumption $y: x^{(0)}(k+1)$ and $y^{(0)}(k+1)$.

Step II: according to the statistical data, average oil unit price $\gamma$, unit industry electricity price $\beta$, and estimated value of limit electricity cost coefficient $\lambda$, are obtained.

Step III: Using the previous two monotonic functions $x^{(0)}(k+1)$ and $y^{(0)}(k+1)$ and some related parameters provided by Step II, electricity consumption expenditure 
function can be represented by $\beta \times y^{(0)}(k+1)$ and the crude oil sales revenue function can be expressed as $\gamma \times x^{(0)}(k+1)$.

Step IV: In terms of Equation (1) and limit electricity cost coefficient $\lambda$, we can construct the following equation $\lambda \times \gamma \times x^{(0)}(k+1)=\beta \times y^{(0)}(k+1)$ to obtain the non-profit time point. Thus the profitable duration can be obtained.

For testing the effectiveness of the proposed procedure, we use Daqing Oil Field as a typical example to predict the profitable duration in the following section.

\section{An Illustrative Example}

In order to illustrate the above computational principle, we select Daqing Oil Field as a typical example to interpret the process of the calculating the profitable duration. Because Daqing Oil Field is the largest oil field of China and a main crude oil production district, selecting it as a representative is rather realistic. According to the current situation, we only collect the following data from Daqing Oil Field Co.Ltd [2], as shown in Table 1.

Table 1. The annual crude output and annual industry electricity consumption of Daqing Oil Field Co. Ltd. (2000-2005)

\begin{tabular}{|c|c|c|c|c|c|c|}
\hline Year & 2000 & 2001 & 2002 & 2003 & 2004 & 2005 \\
\hline $\begin{array}{c}\text { Items } \\
\text { (ten thousand crude output }\end{array}$ & 5,535 & 5,302 & 5,120 & 4,930 & 4,750 & 4,589 \\
\hline $\begin{array}{c}\text { Annual electricity } \\
\text { consumption } \\
\text { (ten thousand KWh) }\end{array}$ & 389,542 & 390,133 & 422,042 & 429,878 & 433,996 & 436,328 \\
\hline
\end{tabular}

Due to the fact that the data are not enough and the existing data show monotonicity, the traditional statistical models are not used. To overcome the data shortage, this paper uses grey forecasting model $\operatorname{GM}(1,1)$, to fit forecast functions of annual crude output and annual electricity consumption respectively.

\subsection{Annual Crude Oil Output Forecasting}

According to the GM, the forecast differential equation of the annual crude oil output can be represented as:

$$
\frac{d x^{(1)}}{d t}+a x^{(1)}=b
$$

According to integral principle, Equation (2) can be transformed into the following form:

$$
x^{(1)}(k+1)=\left(x^{(0)}(1)-\frac{b}{a}\right) e^{-a k}+\frac{b}{a} \quad(k=1,2 \cdots, n)
$$


In term of least squares method, the coefficients of the Equation (3) are obtained:

$$
a=0.04583, b=5613.26, x^{(0)}(1)=5535
$$

Thus the forecast equations of annual crude oil output can be expressed as:

$$
\begin{aligned}
& x^{(1)}(k+1)=-116939 e^{-0.04583 k}+122480 \\
& x^{(0)}(k+1)=x^{(1)}(k+1)-x^{(1)}(k)(k=1,2 \cdots, n)
\end{aligned}
$$

Combining (4) and (5), the final forecasting equation can be given as:

$$
x^{(0)}(k+1)=-116939\left(e^{-0.04583 k}-e^{-0.04583(k-1)}\right)(k=1,2 \cdots, n)
$$

After inspection, the mean relative error and the simulated relative error are as:

$$
\begin{gathered}
\Delta=\frac{1}{6} \sum_{k=1}^{6} \Delta_{k}=0.000581=0.0581 \%<0.01 \\
\Delta_{6}=0.00087=0.087 \%<0.01
\end{gathered}
$$

Therefore, the precision is realistic, and Equation (6) can be used to annual crude oil output prediction.

\subsection{Annual Electricity Consumption Forecasting}

Similar to Section 3.1, the Forecast differential equation of annual electricity consumption can be written as:

$$
\frac{d y^{(1)}}{d t}+p y^{(1)}=q
$$

Through integral computation, the Equation (7) can be represented by:

$$
y^{(1)}(k+1)=\left(y^{(0)}(1)-\frac{q}{p}\right) e^{-p k}+\frac{q}{p} \quad(k=1,2 \cdots, n)
$$

Similarly, we can calculate the parameter values using least squares method:

$$
p=-0.024330, q=387808, y^{(0)}(1)=389542
$$

Using the parameter value, Equation (8) can be written as:

$$
\begin{aligned}
& y^{(1)}(k+1)=16329041 e^{0.24330 k}-15939499 \\
& y^{(0)}(k+1)=y^{(1)}(k+1)-y^{(1)}(k) \quad(k=1,2 \cdots, n)
\end{aligned}
$$


Integrating (9) and (10), we have the following form:

$$
y^{(0)}(k+1)=16329041\left(e^{0.24330 k}-e^{0.24330(k-1)}\right)(k=1,2 \cdots, n)
$$

After inspection, the mean relative error and the simulated relative error are as:

$$
\begin{gathered}
\bar{\Delta}=\frac{1}{6} \sum_{k=1}^{6} \Delta_{k}=0.015232=1.15232 \%<0.05 \\
\Delta_{6}=0.015899=1.5899 \%<0.05
\end{gathered}
$$

Therefore, the precision is also realistic, and formula (11) can be used for annual electricity consumption prediction.

\subsection{Presentation of the Average Industry Electricity Price, Average Oil Price and the Limit Electricity Cost Coefficient}

Because the purpose of this paper is to forecast the profitable duration of the crude oil main production district in China, we directly give the average industry electricity price estimate function and average oil price estimate function according to the data provided by the Daqing Oil Field Co. Ltd [2] and Heilongjiang Electric Power Co., Ltd [3]:

$$
\begin{gathered}
\beta=0.52 \times 1.046^{k}(\mathrm{RMB} / \mathrm{KWh}) \\
\gamma=562.137 \times 0.09334^{\mathrm{k}}(\mathrm{RMB} / \text { ton }) \quad(k=1,2 \cdots, n)
\end{gathered}
$$

After consulting with financial staff in Daqing Oil-Field Company, maximum estimate value of limit electricity cost coefficient that electricity expenditure occupies the crude oil sales revenue: $\lambda=1 / 3$ is offered.

\subsection{Computation of Profitable Duration}

From Section 2, the forecasting functions of the electricity consumption cost and crude oil sales revenue can be expressed by

$$
\begin{aligned}
& E^{(0)}(k+1)=\beta \times y^{(0)}(k+1) \\
& Q^{(0)}(k+1)=\gamma \times x^{(0)}(k+1)
\end{aligned}
$$

According to Equation (1), one has

$$
\lambda \times Q^{(0)}(k+1)=E^{(0)}(k+1)
$$

According to the previous work, we have the following form:

$$
\begin{aligned}
& -116939\left(e^{-0.04583 k}-e^{-0.04583(k-1)}\right) \times 562.137 \times 0.09334^{k} \times 1 / 3 \\
& =0.52 \times 1.046^{k} \times 16329041\left(e^{0.024330 k}-e^{0.024330(k-1)}\right) \quad(k=1,2 \cdots, n)
\end{aligned}
$$




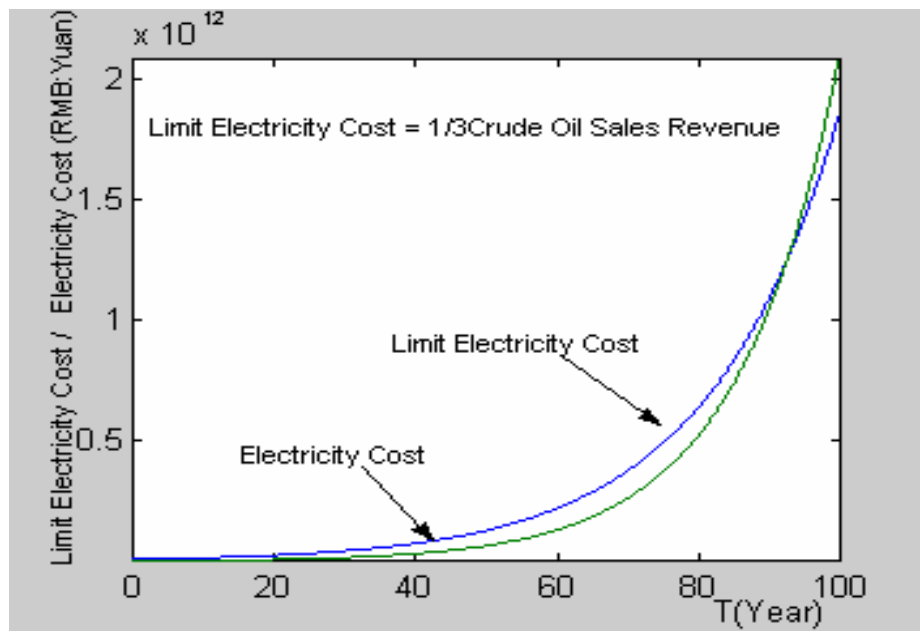

Fig. 1. The time changing of limit electricity cost and electricity cost of the crude oil main production district in China

Equation (15) can be solved by Matlab 6.5, the illustration of the two curves can be shown in Fig. 1.

From Matlab computation and Fig. 1, we can obtain that the intersecting point is $\mathrm{k} \approx 93$. The forecast result shows that the profitable duration of Daqing Oil Field, one crude oil main production district in China, is about 93 years since 2000 if no actions are taken.

\section{Concluding Remarks}

In this study, we utilize GM-based model to predict the profitable duration of Chinese crude oil main production district and obtained a good result. As we know, the crude oil main production district in China takes oil industry as its leading industry. If the oil industry continues developing with the existing crude oil output and electricity consumption mode, it will be non-profitable for the crude oil output after hundreds of years, and thus it will also seriously influence and restrict the existence and development of resource-based cities. According to Equation (1), the key to prolong profitable duration is to increase crude oil output, reduce electricity consumption and decrease limit electricity cost coefficient. Through these ways, it can provide more transformation time for resource-based cities.

\section{References}

1. Deng J.L. Grey System. National Defence Industry Press. 2 (1985) 23-25.

2. Finance department of Daqing oil-field Co., Ltd. The "tenth five-year plan" financial reports of Daqing oil-field Co., Ltd. (confidential document). January 2006.

3. Heilongjiang Electric Power Co., Ltd. The electricity price form of Heilongjiang electric network 2006. September 2006. 